\title{
Crescimento de Componentes Corporais de Três Grupos Genéticos na Fases de Recria e Terminação ${ }^{1}$
}

\author{
Henrique Jorge Fernandes ${ }^{2}$, Mário Fonseca Paulino ${ }^{3}$, Renè Galvão Rezende Martins ${ }^{4}$, \\ Sebastião de Campos Valadares Filho ${ }^{3}$, Robledo de Almeida Torres ${ }^{3}$, Luísa Melville Paiva ${ }^{5}$, \\ Virgínia Aparecida Ribeiro 6
}

RESUMO - Com o objetivo de avaliar a composição do ganho e as curvas de crescimento de componentes corporais, foram utilizados

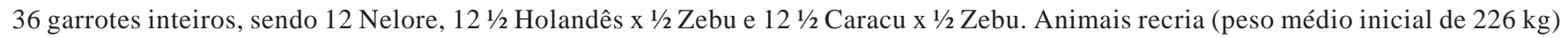
e terminação (peso médio inicial de $332 \mathrm{~kg}$ ) foram mantidos em regime de confinamento até o abate, de acordo com o peso vivo: 310 a $340 \mathrm{~kg}$ para os animais recria e 420 a $470 \mathrm{~kg}$ para os terminação. Foi fornecida a mesma dieta ad libitum a todos os animais. De cada animal abatido pesaram-se os componentes corporais e coletou-se uma amostra da seção HH para avaliação dos componentes físicos das carcaças. Para predição dos conteúdos de músculo, tecido adiposo e ossos da carcaça dos animais e do total de órgãos e de tecido adiposo visceral (TADvis) no corpo vazio, adotou-se a equação de regressão do logaritmo do conteúdo destes componentes no corpo vazio, em função do logaritmo do peso do corpo vazio - PCVz (ARC, 1980). Derivando-se as equações acima, obtiveram-se as equações de predição da participação dos componentes corporais no ganho de $1 \mathrm{~kg}$ de peso de corpo vazio (GPCVz). Dentro de cada grupo genético, todas as características avaliadas foram significativamente correlacionadas com o PCVz dos animais. O tecido ósseo foi o de maturidade mais precoce dentro da carcaça. Entre os componentes corporais estudados, o TADvis foi o de maior alometria para os animais $1 / 2$ Holandês X 1 ² Zebu. A aptidão leiteira do grupo genético reduziu a participação da carcaça no GPCVz, na medida em que aumentou a participação dos órgãos neste ganho. A alometria positiva do tecido muscular, a menor velocidade de incremento no ganho de tecido adiposo da carcaça e a reduzida velocidade de crescimento do tecido ósseo, na fase de terminação dos animais Nelore, podem ser explicados por ganho compensatório realizado por estes animais.

Palavras-chave: composição do ganho, crescimento corporal, Nelore, mestiços

\section{Growth of Body Components of Three Genetic Groups in the Growing and Finishing Phases}

\begin{abstract}
Thirty-six young bulls (12 Nellore, 12 crossbed 1/2 Holstein x 1/2 Zebu, and 12 crossbred 1/2 Caracu x 1/2 Zebu) were used to evaluate the composition of the gain and the growth curves of corporal components. The growing animals had initial average weight of $225 \mathrm{~kg}$, and the finishing ones, initial average weight of $332 \mathrm{~kg}$. The animals were maintained in confinement regime to reach 310 to $340 \mathrm{~kg}$ of weight for the growing animals and 420 to $470 \mathrm{~kg}$ of weight for the finishing ones. A same diet was supplied ad libitum to all the animals. The corporal components of each animal were weighed and a representative sample of the section HH for evaluation of the carcasses physical components was collected. The contents of carcass muscle, carcass fatty tissue and carcass bone and the total of organs and visceral fatty tissue (VFT) in empty body were predict by the equation of regression of the logarithm of the content of these corporal components in the empty body, on the logarithm of the empty body weight - EBW (ARC, 1980). By deriving the equations above, the equations of prediction of the participation of the corporal components in the gain of $1 \mathrm{~kg}$ of empty body weight (EBWG) were obtained. In each genetic group, all the characteristics were significantly correlated with the EBW of the animal. The results showed that the bone tissue was of more precocious maturity in the carcass. VFT was the highest alometric coefficient to the $1 / 2$ Holstein $x \frac{1}{2} 2$ Zebu animals. The milk aptitude reduced the participation of the carcass in the EBWG, as the participation of the organs in this gain increased. The positive alometric development of muscle, the smaller increase velocity in the carcass fatty tissue gain and the smaller decrease velocity in the carcass bone gain in the finishing phase, in Nelore animals may be caused by Nelore compensatory growth.
\end{abstract}

Key Words: body development, composition of the gain, crosssbred, Nellore

\footnotetext{
1 Parte da Dissertação de Mestrado do primeiro autor. Projeto parcialmente financiado pela FAPEMIG.

2 Professor do curso de Zootecnia da Universidade Estadual de Mato Grosso do Sul - UEMS (henrique@zootecnista.com.br).

${ }^{3}$ Professor do Departamento de Zootecnia da Universidade Federal de Viçosa - UFV (mpaulino@ufv.br).

${ }^{4}$ Médico Veterinário, Doutor em Zootecnia pela UFV (renegalvao@yahoo.com).

${ }^{5}$ Professora do curso de Zootecnia da Universidade Estadual de Mato Grosso do Sul - UEMS (luisa@uems.br; lumelville@terra.com.br).

6 Aluna do curso de Agronomia/UFV.
} 


\section{Introdução}

A produção animal, no sentido empresarial, pode ser medida não como ganho de peso vivo ou de peso de corpo vazio, mas sim como ganho de carne comercializável. O conhecimento das curvas de crescimento das diferentes partes do animal, em diferentes grupos genéticos, permite a compreensão das variações no desempenho, nas exigências nutricionais, entre outros. Durante o crescimento, os animais não aumentam apenas o peso e o tamanho, mas também sofrem alterações nas proporções com que os tecidos são depositados no ganho. Esta proporção de tecidos (e de componentes químicos do corpo animal) sofre ainda influência da raça, do sexo e do nível de ingestão de energia, na dependência da proporção dos outros nutrientes (Castillo Estrada, 1996). Oliveira (1999) destaca que o conhecimento sobre crescimento e desenvolvimento corporal de bovinos é importante para subsidiar a melhoria da produção e da produtividade dos rebanhos de corte. Segundo Jorge et al. (1998), a proporção e a velocidade com que os tecidos se acumulam no corpo influenciam o ganho de peso vivo e a eficiência alimentar. Signoretti et al. (1999a) definiram como ponto crucial o conhecimento das possibilidades de manipulação do crescimento: quais os tecidos e os componentes químicos envolvidos e qual proporção desses pode ser manipulada pela nutrição.

Almeida et al. (2001b) relatam que as curvas de crescimento de tecidos individuais e órgãos apresentam crescimento sigmoidal, porém com taxas de crescimento máximo em momentos diferentes, impossibilitando sua superposição. Oliveira (1999) complementa este raciocínio afirmando que a desaceleração do crescimento ocorre mais precocemente nos órgãos vitais, em seguida nos ossos e músculos, com paralela aceleração do crescimento dos tecidos adiposos.

Segundo Castillo Estrada (1996), o estádio de desenvolvimento no momento do abate tem grande influência na composição da carcaça, em que os músculos e o tecido adiposo são os grandes responsáveis pelas variações e o tecido ósseo é relativamente constante.

Black (1989), citado por Oliveira (1999), evidencia as diferenças entre os grupos genéticos quanto ao modelo de desenvolvimento ou à velocidade de formação dos tecidos e dos órgãos. Estas diferenças parecem estar ligadas a diferenças no tamanho do corpo adulto e à produção hormonal dos vários grupos genéticos. Owens et al. (1993) citaram ainda efeitos de temperatura ambiente, comprimento do dia, doenças, parasitas e exercícios, capazes de interferir na curva de crescimento dos componentes corporais, mas que não estariam totalmente esclarecidos.

Lana et al. (1992), analisando o ganho de peso de zebuínos e de mestiços, observaram que zebuínos apresentam maturidade fisiológica mais precoce. Além disso, os zebuínos tendem a depositar mais gordura periférica que os animais de origem leiteira (Peron et al., 1993). Fontes (1995) observou que a maior variação ocorrida dentro da composição do ganho é de gordura depositada, com participação variando de $123 \mathrm{~g}$ a $1 \mathrm{~kg}$ de gordura por $\mathrm{kg}$ de ganho de peso de corpo vazio (GPCVz), em machos Nelore e mestiços, castrados ou não, e com peso vivo entre $200 \mathrm{e} 450 \mathrm{~kg}$.

Castillo Estrada (1996) ressalta que a proporção de gordura no ganho pode ser afetada também pelo consumo de energia acima da mantença e pelo uso de implantes ou hormônios.

Oliveira (1999) observou que animais submetidos à restrição alimentar que não ocasione perda de peso acentuada dos órgãos apresentaram crescimento mais acentuado da carcaça que dos outros componentes corporais, para animais acima de 20 meses de idade. Esse autor observou ainda que animais sob alimentação restrita, após restrição alimentar, apresentaram coeficiente alométrico do tecido muscular da carcaça menor que $1 \mathrm{e}$ do tecido ósseo maior que 1 , inversamente ao esperado e ao observado em animais alimentados à vontade. A análise da participação dos tecidos no ganho de peso indicou decréscimo no conteúdo de ossos e aumento no conteúdo de músculos e de tecido adiposo. Este autor reportou ainda alometria negativa para os componentes não-integrantes da carcaça, com exceção da cabeça.

Guimarães (1999) afirma que ganho compensatório é observado somente quando o período e a intensidade da restrição permitem ao animal adaptação ao estado nutricional mais baixo. Além disso, a composição e a própria proporção do peso vivo recuperado dependem da idade à época da restrição, da duração do período de recuperação, da taxa de ganho e da qualidade do alimento durante a recuperação. Esse autor afirma ainda que a recuperação de peso de cada componente da carcaça no período de recuperação tende a restaurar a composição de animais em alimentação contínua. Se houver tempo no período de recuperação, este objetivo poderá ser alcançado. Berg \& Butterfield (1976), por sua vez, afirmaram que, caso não haja tempo ou condições de o animal recuperar sua composição corporal original durante o período de re-alimentação, normalmente se observa menor proporção de gordura, paralelamente ao

R. Bras. Zootec., v.34, n.1, p.288-296, 2005 
maior conteúdo de tecido muscular, nos animais submetidos à restrição e re-alimentação que naqueles com crescimento ininterrupto.

Guimarães (1999) também destaca que diversas variações na deposição de tecidos na carcaça podem ocorrer durante o ganho compensatório, dependendo das condições da restrição alimentar e da realimentação, mas semprebuscandooretornoauma condiçãocorporal normal.

Segundo Almeida (2000), em condições de consumo limitado, a taxa de ganho compensatório é reduzida, e este ganho é composto principalmente de proteína e água. Em trabalho subseqüente (Almeida et al., 2001a), foram apresentados dados mostrando maior depósito de proteína e nenhuma diferença no depósito de gordura na carcaça por kg de GPCVz, em animais mestiços em ganho compensatório, quando comparados aos alimentados continuamente até os $450 \mathrm{~kg}$ PV.

Neste trabalho, foram avaliadas as equações de crescimento dos componentes corporais e a composição do ganho de peso em bovinos de três grupos genéticos, alimentados com uma mesma dieta, nas fases de recria e terminação.

\section{Material e Métodos}

O presente trabalho foi desenvolvido no laboratório de animais do Departamento de Zootecnia da Universidade Federal de Viçosa.

Foram utilizados 36 garrotes inteiros, sendo 12 Nelore, 12 1/2 Holandês x 1/2 Zebu e 12 1/2 Caracu x 1/2 Zebu, adquiridos de criatórios particulares. Estes animais foram divididos em dois grupos, de acordo com o peso vivo inicial médio. Animais com peso vivo inicial médio próximo a $220 \mathrm{~kg}$ foram definidos como representantes da recria. Os animais com peso inicial próximo a $330 \mathrm{~kg}$ foram classificados como pertencentes à fase de terminação. Em cada fase, foram alocados seis animais de cada grupo genético.

Antes de iniciar o experimento, os animais foram identificados com brincoe submetidos a controle de endo e ectoparasitas e receberam 2.000.000 UI de vitamina A.

Os animais foram distribuídos em baias individuais, com piso concretado com área de $30 \mathrm{~m}^{2}\left(8 \mathrm{~m}^{2}\right.$ cobertos com telhas de amianto e $22 \mathrm{~m}^{2}$ de área descoberta). Todas as baias eram providas de bebedouro e comedouro de cimento.

Após um período de adaptação (sete dias), dois animais de cada um grupo genéticos dentro de cada categoria foram encaminhados para o abate, servindo de referência no estudo da composição corporal.
Os animais restantes foram mantidos em regime de confinamento até o abate, realizado de acordo com o seguinte critério: 310 a $340 \mathrm{~kg}$ de peso vivo, para os animais do grupo recria, e 420 a $470 \mathrm{~kg}$ de peso vivo, para os animais do grupo terminação.

Foi fornecida a mesma dieta para todos os animais. Nesta dieta, $50 \%$ da matéria seca foi concentrado à base de farelo de trigo, de farelo de soja e de milho (Tabela 1), suplementado com minerais. O volumoso, responsável pelos outros $50 \%$ da matéria seca da ração, foi silagem pré-secada de coastcross, adquirida de produtores comerciais. A dieta total foi balanceada, segundo as tabelas de exigência do NRC (1996), para ganho de peso vivo diário de $1,2 \mathrm{~kg}$, utilizando-se o "Sistema Viçosa de formulação de rações" (Lana, 2000), para ajustes, e fornecida aos animais, à vontade, durante todo o período experimental (Tabela 2).

Os animais foram pesados a cada 28 dias. À medida que um animal se aproximava do peso de abate préestabelecido, era definida a data de abate a partir de uma projeção da evolução do peso vivo do animal, com base no ganho de peso médio diário do último período. Antes do abate, os animais foram submetidos a um período de jejum alimentar de 16 horas.

Para predição dos conteúdos de músculo (MC), tecido adiposo (AD) e ossos (OC) da carcaça dos animais e do total de órgãos (OR) e de tecido adiposo visceral (ADvis), no corpo vazio, adotou-se a equação de regressão do logaritmo do conteúdo destes

Tabela 1 - Composição percentual da dieta fornecida aos animais experimentais (\% na MS)

Table 1 - Percent composition of the diet fed to the experimental animals (\% in DM)

\begin{tabular}{lc}
\hline $\begin{array}{l}\text { Ingredientes } \\
\text { Ingredients }\end{array}$ & $\begin{array}{c}\% \mathrm{MS} \\
\% D M\end{array}$ \\
\hline $\begin{array}{l}\text { Silagem pré-secada de coastcross } \\
\text { Coastcross haylage }\end{array}$ & 50,0 \\
$\begin{array}{l}\text { Farelo de trigo } \\
\text { Wheat bran }\end{array}$ & 34,5 \\
$\begin{array}{l}\text { Milho } \\
\text { Corn }\end{array}$ & 12,5 \\
$\begin{array}{l}\text { Farelo de soja } \\
\text { Soybean meal } \\
\text { Mistura mineral* } \\
\text { Mineral mix }\end{array}$ & 2,5 \\
\hline
\end{tabular}

* Calcário calcítico (Calcite limestone) 43,32\%; Cloreto de sódio (Sodium chlorate) 34,41\%; Flor de enxofre (Sulfur flower) 18,69\%; Sulfato de zinco (Zinc sulfate) 3,06\%; lodato de potássio (Potassium iodate) 0,22\%; Sulfato de cobalto (Cobalt sulfate) 0,2\%; Selenito de sódio (Sodium selenite) $0,1 \%$. 
Tabela 2 - Teores médios de matéria seca (MS), matéria orgânica (MO), proteína bruta (PB), extrato etéreo (EE), carboidratos totais (CHOT), fibra em detergente neutro (FDN), carboidratos não-fibrosos (CNF) e nutrientes digestíveis totais (NDT) da silagem, do concentrado e da dieta ${ }^{1}$

Table 2 - Average contents of dry matter (DM), organic matter (OM), crude protein (CP), ether extract (EE), total carbohydrates (CHOT), neutral detergent fiber (NDF), non fiber carbohydrates (NFC) and total digestible nutrients (TDN) of the silage, concentrate and diet

Teores de nutrientes na matéria seca Nutrients contents in the dry matter

\begin{tabular}{|c|c|c|c|c|c|c|c|c|}
\hline & $\operatorname{MS}(\%)$ & $\mathrm{MO}(\%)$ & $\mathrm{PB}(\%)$ & $\mathrm{EE}(\%)$ & CHOT(\%) & $\mathrm{FDN}(\%)$ & $\mathrm{CNF}(\%)$ & $\operatorname{NDT}(\%)^{2}$ \\
\hline & $D M(\%)$ & $O M(\%)$ & $C P(\%)$ & $E E(\%)$ & CHOT (\%) & $N D F(\%)$ & $N F C(\%)$ & $T D N(\%)$ \\
\hline $\begin{array}{l}\text { Silagem pré-secada } \\
\text { Wilted silage }\end{array}$ & 48,00 & 92,05 & 16,87 & 2,49 & 72,69 & 69,60 & 3,09 & - \\
\hline $\begin{array}{l}\text { Concentrado } \\
\text { Concentrate }\end{array}$ & 86,30 & 95,53 & 16,40 & 3,18 & 75,95 & 26,26 & 49,69 & - \\
\hline $\begin{array}{l}\text { Dieta } \\
\text { Diet }\end{array}$ & 67,15 & 93,79 & 16,64 & 2,83 & 74,32 & 47,93 & 26,39 & 68,76 \\
\hline
\end{tabular}

${ }^{1}$ Análises realizadas no Laboratório de Nutrição Animal do Departamento de Zootecnia da UFV.

2 Determinado por meio de ensaio de digestibilidade, considerando-se NDT = PD + CHOD + EED x 2,25 (Sniffen et al., 1992).

${ }_{1}^{1}$ Analyses were performed at the Animal Nutrition Lab/Animal Science Department - UFV.

${ }^{2}$ Determined by means of a digestibility trial, considering TDN $=P D+C H O D+E E D \times 2.25$ (Sniffen et al., 1992).

componentes corporais, em função do logaritmo do peso decorpo vazio (ARC, 1980), conforme o seguinte modelo:

$$
y_{i j}=\mu+b_{i} X_{i j}+e_{i j}
$$

em que $y_{\mathrm{ij}}=$ logaritmo do constituinte corporal do animal j do grupo genético i; $\mu=$ efeito da média (intercepto); $b_{i}=$ coeficiente de regressão do logaritmo do constituinte corporal do animal, em função do logaritmo do peso de corpo vazio, para o grupo genético $\mathrm{i} ; \mathrm{X}_{\mathrm{ij}}=\log$ aritmo do peso de corpo vazio do animal $\mathrm{j}$ do grupo genético $\mathrm{i}$; $\mathrm{e}$ $\mathrm{e}_{\mathrm{ij}}=$ erro aleatório.

Derivando-se as equações de predição do logaritmo dos conteúdos dos componentes corporais, em função do logaritmo do PCVz, obtiveram-se as equações de predição da participação dos componentes corporais no ganho de $1 \mathrm{~kg}$ de $\mathrm{PCV} z$, do tipo:

$$
\mathrm{y}^{\star}=\text { b. } 10^{\mathrm{a} \cdot} \mathrm{X}^{(\mathrm{b}-1)}
$$

em que $y^{6}=$ participação do componente corporal no ganho (kg); a e b = intercepto e coeficiente de regressão, respectivamente, das equações de predição do componente corporal no corpo vazio; $\mathrm{X}=\mathrm{PCVzem}(\mathrm{kg})$

Utilizou-se o procedimento REGRESSION (proc REG) do SAS (SAS, 1989) para estimativa dos coeficientes de correlação e dos parâmetros das equações de regressão do logaritmo dos componentes corporais, em função do logaritmo do PCVz. Adotou-se o nível de significância de 5\% para as análises de variância dos parâmetros estimados.

\section{Resultados e Discussão}

A análise dos dados (Tabela 3) comprovou que todas as características avaliadas foram significativas e altamente correlacionadas com o PCVz dos animais

Tabela 3 - Coeficientes de correlação entre o logaritmo do peso de corpo vazio $(\mathrm{kg})$ e de componentes corporais [tecido muscular da carcaça (MC), tecido adiposo da carcaça (AD), tecido ósseo da carcaça (OC) e dos órgãos (OR) e tecido adiposo visceral (ADvis)], em três grupos genéticos

Table 3 - Correlation coefficients between the logarithm of the empty body weight $(\mathrm{kg})$ and body components [muscle tissue of the carcass (MT), fatty tissue of the carcass (FV), bone tissue of the carcass (BC) and of the organs (OR) and visceral fatty tissue

\begin{tabular}{|c|c|c|c|}
\hline \multirow[t]{2}{*}{$\begin{array}{l}\text { Característica } \\
\text { Trait }\end{array}$} & \multicolumn{3}{|c|}{$\begin{array}{l}\text { Grupo genético } \\
\text { Genetic group }\end{array}$} \\
\hline & $\begin{array}{c}1 / 2 \text { Caracu } x \\
\text { 1/2 Zebu } \\
1 / 2 \text { Caracux } \\
1 / 2 \text { Zebu }\end{array}$ & $\begin{array}{c}\text { 1/2 Holandês x } \\
\text { 1/2 Zebu } \\
1 / 2 \text { Holstein } \\
x^{1 / 2} \text { Zebu }\end{array}$ & $\begin{array}{l}\text { Nelore } \\
\text { Nellore }\end{array}$ \\
\hline $\begin{array}{l}\mathrm{MC}(\mathrm{kg}) \\
M T\end{array}$ & $0,9596 * *$ & $0,9591 * *$ & $0,9892 * *$ \\
\hline $\begin{array}{l}\mathrm{AD}(\mathrm{kg}) \\
F V\end{array}$ & $0,8418 * *$ & $0,8013 * *$ & $0,9926 * *$ \\
\hline $\begin{array}{l}\mathrm{OC}(\mathrm{kg}) \\
B C\end{array}$ & $0,8653 * *$ & $0,9373 * *$ & $0,9393 * *$ \\
\hline $\begin{array}{l}\mathrm{OR}(\mathrm{kg}) \\
O R\end{array}$ & $0,8673 * *$ & $0,7828 * *$ & $0,8105^{* *}$ \\
\hline $\begin{array}{l}\text { ADvis }(\mathrm{kg}) \\
V F T\end{array}$ & $0,9034 * *$ & $0,8497 * *$ & $0,9774 * *$ \\
\hline
\end{tabular}
(VFT)] of three genetic groups 
dentro de cada grupo genético, mostrando que os tecidos da carcaça, os órgãos e o tecido adiposo visceral dos animais acompanharam (em diferentes velocidades) o crescimento do corpo como um todo. Isto sugere que o crescimento destes componentes corporais, em cada grupo genético, pode não ter sofrido influência significativa de outros fatores que não o crescimento corporal do animal como um todo.

A partir das equações de crescimentodos constituintes corporais, pode-se inferirque animais Nelore apresentaram maior capacidade de desenvolvimento de carcaça, enquanto animais $1 / 2$ Holandês $x 1 / 2$ Zebu, crescimento mais acentuado dos órgãos (Tabelas 4, 5 e 6). Este comportamento é coerente com os efeitos observados em animais submetidos à seleção leiteira, que tende a privilegiar animais com maior desenvolvimento de órgãos e vísceras, em razão da maior capacidade de ingestão de alimentos e maior atividade metabólica dos mesmos. Segundo Perón et al. (1993), Signoretti et al. (1999b) e Gesualdi Jr. et al. (2001), o maior tamanho de órgãos dos animais com origem leiteira decorre das maiores exigências nutricionais de mantença. Por outro lado, as raças zebuínas de corte (incluindo a raça Nelore), além de sofrerem uma seleção que privilegia o desenvolvimento da carcaça (para produção de carne), possuem um perfil de adaptação a condições ambientais adversas (em especial a exposição a períodos de baixa disponibilidade de alimentos). Esta situação beneficia animais de baixa exigência de mantença - mais especificamente animais de baixo metabolismo basal, com órgãos e vísceras proporcionalmente menores e menos ativos. Nesse contexto, o grupo genético $1 / 2$ Caracu $x$ 1/2 Zebu, originado do cruzamento de uma raça de dupla aptidão, apresenta resultados intermediários.

Tabela 4 - Parâmetros das equações de regressão do logaritmo de componentes corporais (kg) [tecido muscular da carcaça (MC), tecido adiposo da carcaça (AD), tecido ósseo da carcaça (OC), órgãos (OR) e tecido adiposo visceral (ADvis)], em função do peso de corpo vazio $(\mathrm{kg})$ de três grupos genéticos, nas fases de recria e terminação

Table 4 - Parameters of the logarithm regression equations of the body components[muscle tissue of the carcass (MT), fatty tissue of the carcass (FV), bone tissue of the carcass (BC) and the organs(OR) and visceral fatty tissue (VFT)], as function of the empty body weight $(\mathrm{kg})$, of three genetic groups in the growing and finishing phases

\begin{tabular}{|c|c|c|c|c|c|c|c|}
\hline \multirow[t]{2}{*}{$\begin{array}{l}\text { Característica } \\
\text { Trait }\end{array}$} & \multirow{2}{*}{$\begin{array}{l}\text { Grupo } \\
\text { genético } \\
\text { Genetic } \\
\text { group }\end{array}$} & \multicolumn{3}{|c|}{$\begin{array}{l}\text { Recria } \\
\text { Growing }\end{array}$} & \multicolumn{3}{|c|}{$\begin{array}{l}\text { Terminação } \\
\text { Finishing }\end{array}$} \\
\hline & & Intercepto & $\begin{array}{c}\text { Coeficiente } \\
\text { de regressão }{ }^{1} \\
\text { Regression }^{1} \\
\text { coefficient }^{1}\end{array}$ & $\mathrm{R}^{2}$ & Intercepto & $\begin{array}{c}\text { Coeficiente } \\
\text { de regressão }{ }^{1} \\
\text { Regression } \\
\text { coefficient }^{1}\end{array}$ & $\mathrm{R}^{2}$ \\
\hline $\mathrm{MC}$ & $1 / 2 \mathrm{Car}^{2}$ & 0,2566 & $0,7446^{*}$ & $0,7015^{*}$ & $-0,1071$ & $0,8966^{* *}$ & $0,9631 * *$ \\
\hline$M T$ & $\begin{array}{l}1 / 2 \mathrm{Hol}^{3} \\
\mathrm{Nel}^{4}\end{array}$ & $\begin{array}{r}0,6475^{*} \\
-0,9074^{*}\end{array}$ & $\begin{array}{l}0,5734 * * \\
1,2141 * *\end{array}$ & $\begin{array}{l}0,8571 * * \\
0,9718 * *\end{array}$ & $\begin{array}{l}-0,1059 \\
-0,7327 *\end{array}$ & $\begin{array}{l}0,9012 * * \\
1,1374 * *\end{array}$ & $\begin{array}{l}0,9608 * * \\
0,9622 * *\end{array}$ \\
\hline $\begin{array}{l}\mathrm{AD} \\
F V\end{array}$ & $\begin{array}{l}1 / 2 \mathrm{Car} \\
1 / 2 \mathrm{Hol} \\
\mathrm{Nel}\end{array}$ & $\begin{array}{l}-2,2810 \\
-1,1493 \\
-2,3992 * *\end{array}$ & $\begin{array}{l}1,5326^{*} \\
1,0568^{*} \\
1,6079^{*} *\end{array}$ & $\begin{array}{l}0,7682 * \\
0,7834 * \\
0,9736 * *\end{array}$ & $\begin{array}{l}-5,8282 * * \\
-5,2949 * \\
-2,1394 * *\end{array}$ & $\begin{array}{l}2,8763 * * \\
2,6573 * \\
1,5007 * *\end{array}$ & $\begin{array}{l}0,9616 * * \\
0,7990 * \\
0,9763 * *\end{array}$ \\
\hline $\begin{array}{l}\mathrm{OC} \\
B C\end{array}$ & $\begin{array}{l}1 / 2 \mathrm{Car} \\
1 / 2 \mathrm{Hol} \\
\mathrm{Nel}\end{array}$ & $\begin{array}{l}0,7662 \\
0,0867 \\
0,1513\end{array}$ & $\begin{array}{l}0,2736 \\
0,5634 * * \\
0,5222 *\end{array}$ & $\begin{array}{l}0,2084 \\
0,8622 * * \\
0,7124 *\end{array}$ & $\begin{array}{r}-0,0952 \\
0,4839 \\
-0,2805\end{array}$ & $\begin{array}{l}0,6568 * * \\
0,4350 * \\
0,7235^{* *}\end{array}$ & $\begin{array}{l}0,8762 * * \\
0,6602 * \\
0,9223 * *\end{array}$ \\
\hline $\begin{array}{l}\text { OR } \\
\text { OR }\end{array}$ & $\begin{array}{l}1 / 2 \mathrm{Car} \\
1 / 2 \mathrm{Hol} \\
\mathrm{Nel}\end{array}$ & $\begin{array}{r}-0,3048 \\
-0,4515 \\
0,0839\end{array}$ & $\begin{array}{l}0,5717 \\
0,6370 * * \\
0,3921\end{array}$ & $\begin{array}{l}0,4915 \\
0,9317 * * \\
0,4874\end{array}$ & $\begin{array}{l}-1,2374 * * \\
-3,8311 * * \\
-1,6472 *\end{array}$ & $\begin{array}{l}0,9275 * * \\
1,9407 * * \\
1,0751 * *\end{array}$ & $\begin{array}{l}0,9592 * * \\
0,9560 * * \\
0,9062 * *\end{array}$ \\
\hline $\begin{array}{l}\text { ADvis } \\
V F T\end{array}$ & $\begin{array}{l}1 / 2 \mathrm{Car} \\
1 / 2 \mathrm{Hol} \\
\mathrm{Nel}\end{array}$ & $\begin{array}{l}-3,8958 * \\
-2,1481 * * \\
-3,9811 * *\end{array}$ & $\begin{array}{l}1,9966 * \\
1,2832 * * \\
2,0221 * *\end{array}$ & $\begin{array}{l}0,7889 * \\
0,9099 * * \\
0,9514 * *\end{array}$ & $\begin{array}{l}-6,4404 * * \\
-6,7024 * * \\
-3,0671 * *\end{array}$ & $\begin{array}{l}2,9471 * * \\
3,0295 * * \\
1,6563 * *\end{array}$ & $\begin{array}{l}0,9769 * * \\
0,9712 * * \\
0,9162 * *\end{array}$ \\
\hline
\end{tabular}

* $P<0,05(P<.05)$.

${ }^{* *} \mathrm{P}<0,01(P<.01)$.

1 Coeficiente alométrico (Alometric coefficient).

$21 / 2$ Caracu x 1/2 Zebu (1/2 Caracu x 1/2 Zebu).

$31 / 2$ Holandês $\times 1 / 2$ Zebu (1/2 Holstein $\times 1 / 2$ Zebu).

4 Nelore (Nellore).

R. Bras. Zootec., v.34, n.1, p.288-296, 2005 
Tabela 5 - Participação de componentes corporais $(\mathrm{kg})$ [músculos da carcaça (MC), tecido adiposo da carcaça (AD), tecido ósseo da carcaça (OC), total de carcaça (CAR), órgãos (OR) e tecido adiposo visceral (ADvis)] no ganho de peso de corpo vazio, de três grupos genéticos, em dois pesos vivos, na fase de recria

Table 5 - Participation of body components $(\mathrm{kg})$ [muscles of the carcass (MC); fat tissue of the carcass (FV); bone tissue of the carcass (BC); total of the carcass (CAR), organs (OR); and visceral fatty tissue (VFT)] in the empty body weight gain, of three genetic groups, in two live weight, in the growing phase

\begin{tabular}{|c|c|c|c|c|c|c|c|c|c|}
\hline \multirow[t]{3}{*}{$\begin{array}{l}\text { Grupo genético } \\
\text { Genetic group }\end{array}$} & \multirow[b]{3}{*}{$\begin{array}{l}\text { Peso vivo } \\
\text { Live weigh }\end{array}$} & \multicolumn{8}{|c|}{$\begin{array}{c}\text { Característica } \\
\text { Trait }\end{array}$} \\
\hline & & \multicolumn{2}{|c|}{$\begin{array}{l}\mathrm{MC} \\
M T\end{array}$} & \multicolumn{2}{|c|}{$\begin{array}{l}\mathrm{AD} \\
F V\end{array}$} & \multicolumn{2}{|c|}{$\begin{array}{l}\mathrm{OC} \\
B C\end{array}$} & \multicolumn{2}{|c|}{$\begin{array}{c}\mathrm{CAR}^{1} \\
\text { CAR }^{l}\end{array}$} \\
\hline & & $200 \mathrm{~kg}$ & $310 \mathrm{~kg}$ & $200 \mathrm{~kg}$ & $310 \mathrm{~kg}$ & $200 \mathrm{~kg}$ & $310 \mathrm{~kg}$ & $200 \mathrm{~kg}$ & $310 \mathrm{~kg}$ \\
\hline $\begin{array}{l}1 / 2 \mathrm{Car}^{2} \\
1 / 2 \mathrm{Hol}^{3} \\
\mathrm{Nel}^{4}\end{array}$ & & $\begin{array}{l}0,360 \\
0,282 \\
0,453\end{array}$ & $\begin{array}{l}0,322 \\
0,234 \\
0,498\end{array}$ & $\begin{array}{l}0,125 \\
0,100 \\
0,147\end{array}$ & $\begin{array}{l}0,158 \\
0,103 \\
0,193\end{array}$ & $\begin{array}{l}\text { n.e. } \\
0,072 \\
0,063\end{array}$ & $\begin{array}{c}\text { n.e. } \\
0,060 \\
0,051\end{array}$ & $\begin{array}{l}\text { n.e. } \\
0,454 \\
0,663\end{array}$ & $\begin{array}{c}\text { n.e. } \\
0,397 \\
0,742\end{array}$ \\
\hline $\begin{array}{l}\text { Grupo genético } \\
\text { Genetic group }\end{array}$ & & \multicolumn{8}{|c|}{$\begin{array}{c}\text { Característica } \\
\text { Trait } \\
\end{array}$} \\
\hline & & & & \multicolumn{2}{|c|}{$\begin{array}{l}\text { OR } \\
\text { OR }\end{array}$} & \multicolumn{2}{|c|}{$\begin{array}{c}\text { ADVis } \\
V F T\end{array}$} & & \\
\hline & $\begin{array}{l}\text { Peso vivo } \\
\text { Live weight }\end{array}$ & & & $200 \mathrm{~kg}$ & $310 \mathrm{~kg}$ & $200 \mathrm{~kg}$ & $310 \mathrm{~kg}$ & & \\
\hline $\begin{array}{l}1 / 2 \mathrm{Car} \\
1 / 2 \mathrm{Hol} \\
\mathrm{Nel}\end{array}$ & & & & $\begin{array}{c}\text { n.e. } \\
0,035 \\
\text { n.e. }\end{array}$ & $\begin{array}{c}\text { n.e. } \\
0,029 \\
\text { n.e. }\end{array}$ & $\begin{array}{l}0,043 \\
0,039 \\
0,041\end{array}$ & $\begin{array}{l}0,067 \\
0,044 \\
0,064\end{array}$ & & \\
\hline
\end{tabular}

$1 \mathrm{CAR}=\mathrm{MC}+\mathrm{AD}+\mathrm{OC}(C A R=M T+F V+B C)$.

$21 / 2$ Caracu $x 1 / 2$ Zebu (1/2 Caracu $x$ 1/2 Zebu).

$31 / 2$ Holandês $\times 1 / 2$ Zebu $(1 / 2$ Holstein $\times 1 / 2$ Zebu)

4 Nelore (Nellore).

5 Não-estimado (Not estimated).

Tabela 6 - Participação de componentes corporais $(\mathrm{kg})$ [músculos da carcaça (MC); tecido adiposo da carcaça (AD); tecido ósseo da carcaça (OC); total de carcaça (CAR); órgãos (OR); e tecido adiposo visceral (ADvis)] no ganho de peso de corpo vazio, de três grupos genéticos, em dois pesos vivos, na fase de terminação

Table 6 - Participation of body components ( $\mathrm{kg}$ ) [muscles of the carcass (MC); fat tissue of the carcass (FV); bone tissue of the carcass (BC); total of the carcass (CAR), organs (OR); and visceral fatty tissue (VFT)] in the empty body weight gain, of three genetic groups, in two live weight, in the finishing phase

Grupo genético

Genetic group

\begin{tabular}{|c|c|c|c|c|c|c|c|c|}
\hline \multirow[b]{3}{*}{$\begin{array}{l}\text { Peso vivo } \\
\text { Live weigh }\end{array}$} & \multicolumn{8}{|c|}{$\begin{array}{c}\text { Característica } \\
\text { Trait }\end{array}$} \\
\hline & \multicolumn{2}{|c|}{$\begin{array}{l}\mathrm{MC} \\
M T\end{array}$} & \multicolumn{2}{|c|}{$\begin{array}{l}\mathrm{AD} \\
F V\end{array}$} & \multicolumn{2}{|c|}{$\begin{array}{l}\mathrm{OC} \\
B C\end{array}$} & \multicolumn{2}{|c|}{$\begin{array}{l}\mathrm{CAR}^{1} \\
\text { CAR }^{1}\end{array}$} \\
\hline & $340 \mathrm{~kg}$ & $450 \mathrm{~kg}$ & $340 \mathrm{~kg}$ & $450 \mathrm{~kg}$ & $340 \mathrm{~kg}$ & $450 \mathrm{~kg}$ & $340 \mathrm{~kg}$ & $450 \mathrm{~kg}$ \\
\hline & 0,389 & 0,378 & 0,185 & 0,312 & 0,075 & 0,068 & 0,649 & 0,758 \\
\hline & 0,402 & 0,391 & 0,167 & 0,267 & 0,053 & 0,045 & 0,622 & 0,704 \\
\hline & 0,460 & 0,478 & 0,188 & 0,216 & 0,079 & 0,073 & 0,727 & 0,767 \\
\hline
\end{tabular}

$1 / 2 \operatorname{Car}^{2}$

$1 / 2 \mathrm{Hol}^{3}$

0,460

Característica

Grupo genético

Genetic group

Trait

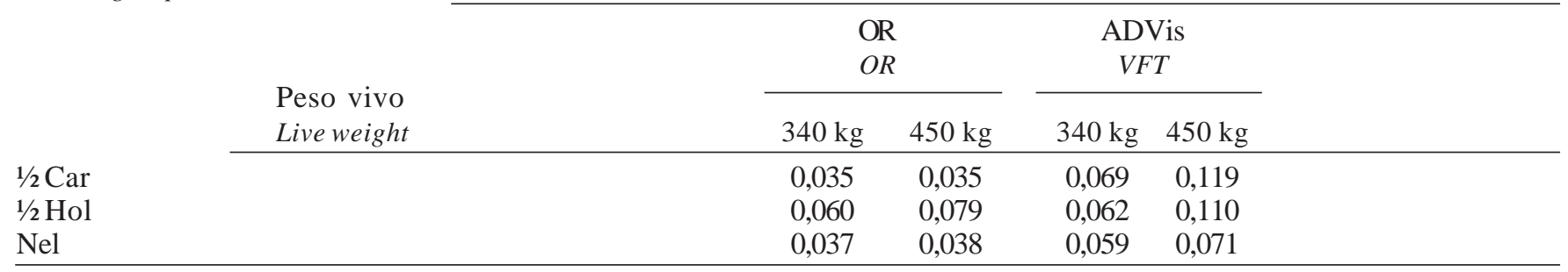

${ }^{1} \mathrm{CAR}=\mathrm{MC}+\mathrm{AD}+\mathrm{OC}(C A R=M T+F V+B C)$.

$21 / 2$ Caracu $\times 1 / 2$ Zebu $(1 / 2$ Caracu $\times 1 / 2$ Zebu).

$31 / 2$ Holandês $\times 1 / 2$ Zebu (1/2 Holstein $\times 1 / 2$ Zebu).

4 Nelore (Nellore).

R. Bras. Zootec., v.34, n.1, p.288-296, 2005 
O Nelore apresentou comportamento diferente dos demais grupos genéticos, quando se avaliou a deposição de MC. Em ambas as fases, enquanto os outros grupos reduziram a velocidade de crescimento dos músculos, com o avanço da idade, os animais Nelore depositaram cada vez mais este tecido em cada kg de ganho de peso de corpo vazio-GPCVz(Tabela4). Como consequiência, enquanto um animal Nelore (durante a fase de recria) deposita cerca de $132 \mathrm{~g}$ de músculo por kg de GPCVz a mais que a média dos outros grupos genéticos, a um peso vivo de $200 \mathrm{~kg}$, esta diferença cresce para $220 \mathrm{~g}$ a mais de tecido muscular por $\mathrm{kg}$ de GPCVz a um peso vivo de $310 \mathrm{~kg}$. Da mesma forma, na fase de terminação, a diferença entre a deposição de tecido muscular pelo Nelore e a média dos demais grupos genéticos aumenta de 64,5 g por kg de GPCVz, aos $340 \mathrm{~kg}$, para 93,5 g por kg de GPCVz, aos 470 kg (Tabelas 5 e 6).

Segundo Owens et al. (1993) e Freitas (1995), era de se esperar redução na deposição de MC, com o avanço do peso vivo do animal. A hipótese de que os animais Nelore utilizados no experimento apresentariam baixo peso vivo inicial, em decorrência de restrição alimentar severa, ou muito prolongada, durante seu crescimento, poderia explicar um crescimento muscular mais pronunciado para que os animais pudessem compensar seu desenvolvimento retardado. Reforçando estahipótese, Oliveira (1999), também trabalhandocom animais adquiridos de criatórios particulares, portanto sem controle específico e confiável das condições de criação pré-experimentais, obteve alometria positiva para o crescimento de $\mathrm{MC}$ em animais submetidos à alimentação à vontade durante o período experimental, mesmo em idade e pesos avançados. Hornick et al. (1998), citados por Almeida et al. (2001b), destacam que, nestes casos, após determinado período de alimentação à vontade, a taxa de deposição de gordura deve aumentar rapidamente, concomitante à redução na deposição de proteína, graças ao aumento na taxa de insulina, em relação ao hormônio de crescimento. A outra hipótese de que este crescimento muscular acentuado a grandes pesos vivos deveu-se ao maior tamanho corporal adulto deste grupo genético pode ser descartada, pois contraria diversos trabalhos realizados em condições brasileiras (Lana et al., 1992; Castillo Estrada et al., 1997), que classificam o Nelore como uma raça de maturação precoce, e o próprio comportamento observado do MC (mesmo animais tardios deveriam apresentar coeficiente alométrico do MC < 1).

Analisando-se o crescimento do $\mathrm{AD}$, todos os grupos genéticos, em ambas as fases, mostraram comportamento semelhante, com maiores deposições de $\mathrm{AD}$ por $\mathrm{kg}$ de GPCVz, à medida que se aumenta o peso vivo do animal. Na fase de recria, observa-se maior velocidade de deposição de AD nos animais $1 / 2$ Caracu $\mathrm{X} 1 / 2$ Zebu e nos animais Nelore, enquanto os animais $1 / 2$ Holandês $\mathrm{x} 1 / 2$ Zebu apresentam alometria próxima a 1 (Tabela 4). Paralelamente, na fase de terminação, observa-se que o grupo Nelore apresentou coeficiente alométrico menor que os demais. Esta menor velocidade de incremento no ganho de tecido adiposo da carcaça, à medida que o animal cresce, também pode ser atribuída a um possível ganho compensatório realizado por estes animais, que ainda estejam tentando recompor sua composição corporal original a este peso, priorizando o depósito de músculos (Berg \& Butterfield, 1976).

Todos os grupos, em ambas as categorias, mostraram decréscimos na velocidade de crescimento do OC. Devido à falta de ajustes dos dados, não se estimou a participação do OC e, conseqüentemente, do CAR, no GPCVz dos animais $1 / 2$ Caracu $x$ 1/2 Zebu na fase de recria (Tabela 5). Oliveira (1999) e Almeida et al. (2001a) observaram que o tecido ósseo foi o de maturidade mais precoce dentro da carcaça, por ter apresentado decréscimo da taxa de crescimento mais acentuado (coeficiente alométrico mais negativo) que o MC (Tabela 4). Neste aspecto, o grupo genético Nelore apresentou menor redução da velocidade de crescimento na fase de terminação, diminuindo a deposição de OC cerca de $6 \mathrm{~g}$ por $\mathrm{kg}$ de GPCVz, entre 340 e $450 \mathrm{~kg}$ de peso vivo, enquanto os outros grupos genéticos reduziram a deposição deste tecido, em média, em 7,5 g por kg de GPCVz nesta mesma faixa de peso (Tabela 6). Este comportamento também pode ser explicado pela ocorrência de crescimento compensatório, que poderia manter maior crescimento de ossos no grupo genético Nelore, mesmo a maiores pesos vivos, como forma de o animal tentar recuperar seu tamanho original, reduzido pela restrição nutricional.

As equações de crescimento dos OR (Tabela 4) mostram a maturidade precoce destes, constatada por Berg \& Butterfield (1976) e evidenciada em condições brasileiras também por Perón et al. (1993), Guimarães (1999) e Jorge et al. (1999). Não foram estimadas as participações dos OR no GPCVz dos grupos genéticos $1 / 2$ Caracu X $1 \frac{2}{2}$ Zebu e Nelore, na fase de recria, em razão da falta de ajuste dos dados (Tabela 5). A análise dos dados da terminação indicou alometria positiva tanto para os animais $1 / 2$ Holandês $x 1 / 2$ Zebu, quanto para os Nelore (Tabela 4). O grande coeficiente alométrico apresentado pelos animais $1 \frac{1}{2}$ Holandês $x$ 1 12 Zebu, para

R. Bras. Zootec., v.34, n.1, p.288-296, 2005 
o crescimento de órgãos nesta fase $(1,94)$, pode ser explicado pelo fato destes animais serem descendentes de uma raça submetida à seleção leiteira intensiva (o que tende a privilegiar animais com maior desenvolvimento de órgãos e vísceras). O coeficiente alométrico positivo $(1,07)$ dos animais Nelore, por sua vez, pode estar ligado a maior desenvolvimento dos órgãos visando suprir maior demanda metabólica para a recuperação da condição corporal original dos animais. O modelo proposto por Berg \& Butterfield (1976) também prevê que os órgãos são os primeiros tecidos a demandarem nutrientes durante um processo de recuperação da condição corporal, após restrição nutricional.

Oliveira (1999), trabalhando com animais 3/4 GirHolandes, também encontrou coeficientes alométricos mais acentuados para deposição de gordura interna que para a deposição de tecido adiposo da carcaça (Tabela 4). De modo geral, comparando-se os grupos na fase de recria, os animais $1 / 2$ Holandês $x 1 / 2$ Zebu apresentaram menor participação do ADvis no ganho de peso que os outros grupos genéticos (Tabela 5). Apesar disso, entre os componentes corporais estudados, o ADvis foi o de maior alometria para os animais $1 / 2$ Holandês $x 1 / 2$ Zebu, em ambas as fases de recria e terminação, comprovando importância deste tecido para o metabolismo destes animais. Por outro lado, o pequeno coeficiente alométrico do ADvis apresentado pelos animais Nelore na fase de terminação, em relação aos demais grupos genéticos (Tabela 4), evidencia maior tendência deste grupo genético em depositar suas reservas energéticas no tecido adiposo da carcaça (Tabela 6).

\section{Conclusões}

Animais com aptidão leiteira apresentam participação menor de carcaça e maior de órgãos e tecido adiposo visceral no ganho de peso de corpo vazio.

O tecido ósseo apresenta maturidade mais precoce e o adiposo, mais tardia.

A alometria dos tecidos da carcaça e dos órgãos e a participação destes componentes corporais no ganho de peso dos animais do grupo genético Nelore foram influenciadas pelo ganho compensatório realizado por estes animais.

\section{Literatura Citada}

AGRICULTURAL RESEARCH COUNCIL - ARC. The nutrient requirements of ruminants livestock. England: Commonwealth Agricultural Bureaux, 1980.351p.

R. Bras. Zootec., v.34, n.1, p.288-296, 2005
ALMEIDA, M.I.V. Conteúdo corporal e exigências nutricionais de proteína, energia e macroelementos minerais de novilhos mestiços holandês-gir em ganho compensatório. Viçosa, MG: Universidade Federal de Viçosa, 2000. 121p. Tese (Doutorado em Zootecnia) - Universidade Federal de Viçosa, 2000.

ALMEIDA, M.I.V.; FONTES, C.A.A.; ALMEIDA, F.Q. et al. Avaliação do crescimento de tecidos e órgãos de novilhos mestiços holandês-gir durante o ganho compensatório. 1. Carcaça. Revista Brasileira de Zootecnia, v.30, n.2, p.526-534, 2001 a.

ALMEIDA, M.I.V.; FONTES, C.A.A.; ALMEIDA, F.Q. et al. Avaliação do crescimento de tecidos e órgãos de novilhos mestiços holandês-gir durante o ganho compensatório. 2 . Tecidos e órgãos. Revista Brasileira de Zootecnia, v.30, n.2, p.535-545, 2001b.

BERG, R.T.; BUTTERFIELD, R.M. New concepts of cattle growth. Sidney: Sidney University Press, 1976. 240p.

CASTILLO ESTRADA, L.H.; FONTES, C.A.A.; JORGE, A.M. et al. Exigências nutricionais de bovinos não-castrados em confinamento. 1. Conteúdo corporal e exigências líquidas de proteína e energia para ganho de peso. Revista Brasileira de Zootecnia, v.26, n.3, p.575-583, 1997.

CASTILLO ESTRADA, L.H. Composição corporal e exigências de proteína, energia e macroelementos minerais $(\mathbf{C a}, \mathbf{P}$, Mg, Na e K), características da carcaça e desempenho do Nelore e mestiços em confinamento. Viçosa, MG: Universidade Federal de Viçosa, 1996. 129p. Tese (Doutorado em Zootecnia) - Universidade Federal de Viçosa, 1996.

FONTES, C.A.A. Composição corporal, exigências liquidas de nutrientes para ganho de peso e desempenho produtivo de animais zebuínos e mestiços europeu-zebu. Resultados experimentais. In: SIMPÓSIO INTERNACIONAL SOBRE EXIGÊNCIAS NUTRICIONAIS DE RUMINANTES, 1995, Viçosa, MG. Anais... Viçosa, MG: Universidade Federal de Viçosa, 1995. p.419-455.

FREITAS, J.A. Composição corporal e exigência de energia e proteína de bovinos (zebuínos e mestiços) e bubalinos não castrados, em confinamento. Viçosa, MG: Universidade Federal de Viçosa, 1995. 75p. Dissertação (Mestrado em Zootecnia) - Universidade Federal de Viçosa, 1995.

GESUALDI JUNIOR, A.; VELOSO, C.M.; PAULINO, M.F. et al. Níveis de concentrado na dieta de bovinos F1 Limousin x Nelore: peso dos órgãos internos e trato digestivo. Revista Brasileira de Zootecnia, v.30, n.6, p.1866-1871, 2001.

GUIMARÃES, R.F. Ganho de peso, consumo e conversão alimentar, composição corporal e características de carcaça de novilhos mestiços durante o ganho compensatório. Viçosa, MG: Universidade Federal de Viçosa, 1999. 111p. Tese (Mestrado em Zootecnia) - Universidade Federal de Viçosa, 1999.

JORGE, A.M.; FONTES, C.A.A.; PAULINO, M.F. et al. Desempenho produtivo de animais de quatro raças zebuínas, abatidos em três estádios de maturidade. 1. Ganho de peso e de carcaça e eficiência de ganho. Revista Brasileira de Zootecnia, v.27, n.4, p.766-769, 1998.

JORGE, A.M.; FONTES, C.A.A.; PAULINO, M.F. et al. Tamanho relativo dos órgãos internos de zebuínos sob alimentação restrita e ad libitum. Revista Brasileira de Zootecnia, v.28, n.2, p.374-380, 1999.

LANA, R.P. Sistema Viçosa de formulação de rações. Viçosa, MG: Universidade Federal de Viçosa, 2000. 60p.

LANA, R.P.; FONTES, C.A.A.; PERON, A.J. et al. Composição corporal e do ganho de peso e exigências de energia, proteína e 
macroelementos minerais ( $\mathrm{Ca}, \mathrm{P}, \mathrm{Mg}, \mathrm{Na}$ e K), de novilhos de cinco grupos raciais. 1. Conteúdo corporal e do ganho de peso em gordura, proteína e energia. Revista Brasileira de Zootecnia, v.21, n.3, p.518-527, 1992.

NATIONAL RESEARCH COUNCIL - NRC. Nutrient requirements of beef cattle. 7.ed. Washington, D.C., 1996. $242 p$.

OLIVEIRA, R.C. Ganho de peso, características de carcaça e composição corporal de novilhos em regime de pastejo em capim elefante durante a estação chuvosa. Viçosa, MG: Universidade Federal de Viçosa, 1999. 109p. Dissertação (MestradoemZootecnia)-Universidade Federal de Viçosa, 1999.

OWENS, F.N.; DUBESKI, P.; HANSON, C.F. Factors that alter the growth and development of ruminants. Journal of Animal Science, v.71, p.3138-3150, 1993.

PERON, A.J.; FONTES, C.A.A.; LANA, R.P. et al. Tamanho de órgãos internos e distribuição da gordura corporal em novilhos de cinco grupos genéticos, submetidos à alimentação restrita e ad libitum. Revista Brasileira de Zootecnia, v.22, n.5, p.813-819, 1993.
SAS INSTITUTE INC. 1989. SAS/STAT User's Guide, Version 6. 4.ed. Cary, NC: SAS Institute Inc. 943p.

SIGNORETTI, R.D.; SILVA, J.F.C.; VALADARES FILHO, S.C. et al. Composição corporal e exigências líquidas de energia e proteína de bezerros da raça holandesa alimentados com dietas contendo diferentes níveis de volumoso. Revista Brasileira de Zootecnia, v.28, n.1, p.195-204, 1999a.

SIGNORETTI, R.D.; ARAÚJO, G.G.L.; SILVA, J.F.C. et al. Características quantitativas das partes do corpo não-integrantes da carcaça animal e desenvolvimento do trato gastrintestinal de bezerros da raça holandesa alimentados com dietas contendo quatro níveis de concentrado. Revista Brasileira de Zootecnia, v.28, n.4, p.875-882, 1999 b.

SNIFFEN, C.J.; O'CONNOR, J.D.; Van SOEST, P.J. et al. A net carbohydrate and protein system for evaluating cattle diets: II - Carbohydrate and protein availability Journal of Animal Science, v.70, p.3562-3577, 1992.

Recebido em: 04/02/03

Aceito em: 26/10/04 